\title{
The Patterns and Reasons of Committing Crimes in The Jordanian Society from The Perspectives of Inmates in Ma'an Reform and Rehabilitation Center
}

\author{
Dr. Abdullah Salem Al-Darawsheh \\ Dr. Wala' AbdulFattah Al-Sarayreh \\ Dr. Khalil Ibrahim Al-Hilalat \\ Dr. Sami Fawwaz Al-Jazi
}

Received: Dec. 12, 2018 Accepted: Jan. 8, 2019 Published: February 1, 2019

doi:10.5296/jse.v9i1.13822 URL: https://doi.org/10.5296/jse.v9i1.13822

\begin{abstract}
This study aimed at identifying the patterns and reasons of committing crimes in the Jordanian society from the perspectives of inmates in Ma'an reform and rehabilitation center. In order to achieve the study objectives, the researchers developed a questionnaire for data collection, and selected a simple random sample to detect the study sample. The study sample consisted of (105) individuals, and concluded the following:

The results showed that the most common crime patterns in the Jordanian society from the perspectives of inmates in Ma'an reform and rehabilitation center are the murder crimes which were in the first rank, with a mean of (4.88) and a standard deviation of (0.47), followed by drug trafficking with a mean of (4.75) and a standard deviation of $(0.42)$, robbery crimes with a mean of (4.55) and a standard deviation of (0.52), and finally incest crimes with a mean of (3.01) and a standard deviation of (0.63).

The results showed that the most common reasons leading to crimes the Jordanian society from the perspectives of inmates in Ma'an reform and rehabilitation center are the bad partners which were in the first rank, with a mean of (4.81) and a standard deviation of (0.42), followed by family disintegration with a mean of (4.65) and a standard deviation of (0.40), and then poverty with a mean of (4.30) and a standard deviation of (0.51), and finally the feeling of neglect and rejection by others with a mean of (3.99) and a standard deviation of (0.67).
\end{abstract}

The study concluded with a number of recommendations.

Keywords: crime, reform and rehabilitation center, inmate. 


\section{MlMacrothink}

\section{Introduction}

The crime is a social phenomenon that is prevalent in different human societies either in the developing or developed ones. It has existed since the human beings lived in groups. The Holy Quran referred to the first murder crime committed on the Earth when Qabeel killed his brother Habeel. The crime develops quantitatively and qualitatively along with the development of mankind as well as the development of societies in addition to their technical and financial potentials.

The crime is still threatening the human societies, and it is manifested in different forms such as robbery, violence, rape, economic crimes, organized crimes as well as group crimes that threaten the safety and stability of human societies. It has devastating consequences on both the individual and the society, in addition to its close correlation with values, customs and traditions, as well as the economic, social and political circumstances that tackle the human societies. The technological advancement in the contemporary era contributed to changing the world into a small village. Therefore, the social networks have a prominent role in increasing the rates of committing crimes and exceeding the geographical borders of countries (Al-Badayneh, 2003).

The world is also witnessing a rapid increase in the pace of crime committing due to the conflicts and disputes between individuals and groups; where there are severe powers that stimulate the individual to do the delinquent behavior, such as the political, economic, social, psychological, and cultural motives; and thus, we should combat the different types of crime, identify its causes and explain it in order to find the appropriate ways for dealing with it.

The Hashemite Kingdom of Jordan as a part of this world also witnessed a remarkable change and development which was manifested by the transition from a traditional society into a civilized and industrial one which was, in turn, reflected by an increase in the rates of crime committing in the Jordanian society( Al-Badayneh, 2003).

Therefore, this study aims at identifying the patterns and reasons of committing crimes in the Jordanian society from the perspectives of inmates in Ma'an reform and rehabilitation center.

\section{The study problem and questions}

The rates of crime committing have increased in the Jordanian society and turned into a real risk that threatens the safety and stability of the society. In order to identify the patterns and reasons of crimes committing, this study aimed at detecting these patterns and reasons from the perspectives of inmates in Ma'an reform and rehabilitation center. Therefore, this study aims at answering the following questions:

1- What are the patterns of the crimes committed in the Jordanian society from the perspectives of inmates in Ma'an reform and rehabilitation center?

2- What are the reasons of the crimes committed in the Jordanian society from the perspectives of inmates in Ma'an reform and rehabilitation center? 


\section{Macrothink}

3- Are there statistically significant differences at $(\alpha \leq 0.05)$ regarding the reasons leading to crimes committed in the Jordanian society from the perspectives of inmates in Ma'an reform and rehabilitation center due to the variables of age, income level, educational level, and marital status?

\section{The study objectives}

1- Identifying the patterns of the crimes committed in the Jordanian society from the perspectives of inmates in Ma'an reform and rehabilitation center.

2- Identifying the reasons for the crimes committed in the Jordanian society from the perspectives of inmates in Ma'an reform and rehabilitation center.

3- Identifying whether there are statistically significant differences regarding the reasons leading to crimes committed in the Jordanian society from the perspectives of inmates in Ma'an reform and rehabilitation center due to the variables of age, income level, educational level, and marital status?

\section{The study importance}

The importance of this study lies in addressing a vital topic related to society security. The study also aimed at identifying the patterns and reasons of committing crimes in the Jordanian society from the perspectives of inmates in Ma'an reform and rehabilitation center, where the crime became a source of anxiety that threatens the security of the human societies as it provokes stress and anger among individuals and groups. Therefore, this study stems from two main considerations:

\subsection{The theoretical importance}

This study represents a scientific addition and supply for both the Jordanian and Arabic libraries with regard to the domain of addressing the patterns and reasons of committing crimes in the Jordanian society. The researcher hopes that the current study would be a base for conducting further studies that address the topic of crime in a comprehensive and scientific manner and contribute to achieving the enrichment of research as well as cognitive accumulation.

\subsection{The practical importance}

The importance of this study lies in identifying the patterns and reasons for committing crimes in the Jordanian society, where the rates of committing crimes increased along with the brutality of the painful images related to that on the individual and the society as well. Therefore, based on the results of this study, we may recommend about holding seminars and educational programs about the danger of crimes on both individual and the society, setting the remedial and preventive measures that would enable decision makers in the security departments to face the crime and reduce its risks as well as developing the appropriate criminal policies. 


\section{The study terminology}

The terms and scientific concepts:

Linguistically, the word crime is derived from the word cutting and crime is the offend and sin. (Ibn Mandhour, 1994)

The standard definition of crime is performing or not performing an action which is done by a mature person who can be sentenced by law with a certain sanction or punishment. (Nasha'at, 1998)

The procedural definition of crime is the action that causes harm to both individuals and community and which forms a behavior that contradicts with the social traditions. Crime is also defined as any action which merits a punishment with jail or fine whether it is a crime or an offence.

The inmate is the person who is legally forbidden from acting by himself or doing his own religious and social activities (IbnTaimiyya, 2005)

\section{Reform and rehabilitation center:}

Its mission is to keep inmates as well as providing the necessary care for them and applying reform programs that help them to reengage in the society. In addition to other programs which aim at enabling them to have a good living (Al-Zoraiqat, 2009)

\section{The theoretical framework}

The word crime refers to committing any deviant action and this word is derived from the act related to committing a sin. (Abu Zahra,1998)

From a social perspective, crime is considered as a negative social phenomenon that represents a dysfunction within the social relationships and behaviors; it embodies the nature of contradictions within the objective and the subjective variables affecting the human environment and social life as well as diagnosing the nature of human difficulties experienced by both individuals and groups. (Al-Hassan and Ihssan, 1993)

(Durkheim, 1984) suggests that crime is necessary for a healthy society ; it is considered as integral part for each healthy society as it occurs naturally in societies. He also suggests that the more the community is developed, the more the work is divided and the more the social system is sophisticated, a state of lack to integration is emerged which, in turn, increases the state of disharmony between individuals in the society and weakens its social power. (Badawi, 1974)

Psychologically, crime is defined as expressing the emotional power that is enclosed with the individual which leads to an antisocial behavior that doesn't match with the circumstances and traditional allowed by society (Al-Mashahdani, 2005)

Al-Siraj, 1984 suggested that crime is a deviant human behavior that results from disintegration or disorder within a component of the individual personality. 
Legally, crime is defined as a type of deliberate offence against the criminal law which takes place without justifications or reasonable motives and entails punishment by the state security authorities (Jaber, 2007). In addition, Al-Saati (2005) suggested that there is no crime without a legal context.

From the criminology perspective; crime refers to studying the criminal behavior as well as focusing the nature and materials of the criminal activities occurrence, their geographical and social distribution. It also refers to the physical and psychological traits as well as social history of offenders, in addition to the relationships between offence and other antisocial behaviors (Madass, 2003).

According to the criminological perspective, Al-Essawi, (1992) suggests that crime is defined as each human behavior that entails sanction due to the violation of the values of the society and the interests of individuals, and that behavior reflects a deviant self or a criminal composition.

In the Islamic Sharia, crime relates to performing a forbidden activity that entails punishment, or not performing an obligatory activity, where not performing it also entails punishment (Al-Sayid, et al, 204).

(AlMashahdani,2005), based on the sharia concept, suggested that crime is a secular deviance; thus it represents a religious sin that entails punishment in this world an in the afterworld.

The criminologists explain the reasons leading to criminal behaviors as follows:

(S. Lombroso) suggests that crime is biological and inevitable; where the criminal is an ill person who suffers from inherited criminal behavior, known as criminal by instinct, since the criminal is born with a natural readiness that motivated him/her to commit a crime (Al-Wereikat, 2013).

(Degreef) demonstrated that crime is not only a personality feature, but it also reflects a violent time and disconnection related to a mutual contradiction between individuals; this short period of time could be dangerous when the communication pattern is stressful, where the criminal feels that he is rejected by others (Makki,2007).

Meirton suggests that when there is no social balance between the accepted objectives and the methods that lead to achieving them, a distressful feeling is created within the individual and the society which stems from the inability to integrate with the legal methods so as to achieve the desired objectives, and that consequently results in delinquency and committing crimes (Al-Mashahdani,2005).

Southerland suggests that crime is a behavior that the individual acquires from the surrounding environment. The higher the degree of convergence between the individual and the surrounding social environment, the higher the possibility of learning the antisocial behavior and adopting it (A-Shodaifat, et al, 2016).

Almert shows that delinquency at the individual level occurs when that individual commits the antisocial behavior accidentally(initial delinquency), and this behavior is noticed by 
others who classify the individual as a delinquent or criminal; this classification excludes the individual from the circle of traditional interaction with the society and so he/she is engaged in interaction with other offenders; consequently he/she adopts the deviant behavior and culture according to that secondary delinquency (Al-Mashahdani,2005).

Bonjeih believes that crime is one of the manifestations related human behavior, which stems from the selfish nature of the human beings; this selfish feature isn't inherent but mainly acquired. This selfish nature leads to ethical disadvantages which, in turn, lead to crime and delinquency (Al-Wereikat, 2013).

M.Seman suggests that the individual's sense of resentment, isolation and loneliness as well as his feelings related to the loss of social norms that control behavior, make him unable to control his/her behavior (Al-Wereikat, 2013).

Heirshi concluded that the individuals who have high levels of self-adjustment, regardless their age, are less likely to commit criminal and delinquent behaviors (Al-Wereikat, 2013).

Tard attributes crime to a main social and psychological factor, which represents the simulation, where the individual learns from the surrounding nature by imitating the criminal acts of their relatives and friends. He also believes that the criminal behavior is a manner that the individual learns since the early years of childhood, and spreads among the individuals of the society (Al-Wereikat, 2013).

\section{The most important theories that explained crime}

\subsection{The psychological theory}

The advocators of this theory confirm that crime is a psychological activity that reflects a criminal desire. Others demonstrate that crime is a result of mental diseases, such as neurosis and schizophrenia which lead to committing crimes.

Duper suggests that crime is the deviation from instincts, which are divided into three instincts: the instinct of reproduction, socialization, as well as maintaining the human gender (Zein Al-Deen, 1995).

\subsection{The theory of psychoanalysis (Sigmund Freud)}

This theory demonstrates the criminal behavior based on the psychological aspect of the individual, since the conflict that takes place between the personality components leads to its distinction. According to Freud, personality is considered as the foundation stone and consists of three types (Al-Sa'ati, 2005):

1- The (Id): it represents the instinctive motives, forbidden tendencies and desires; the principle of pleasure has nothing to do with the real world.

2- The Ego: the emotional and volitional domain, which represents the locus of control and serves as a compromising factor between the demands of the (Id) on the one hand and the external reality demands on the other hand. 
3- The super ego: It is the unconscious side of personality; it consists of the ethical values, norms and beliefs. Indeed, it is the conscience that prevents the individual's development; it opposes the (ego), but obeys the (Id).

Freud suggests that guilt underlies many manifestations of criminal behavior. Crime is attributed to setbacks in the process of identification which is the main stimulation in socialization. This type of abnormality leads to unhealthy growth; which leads to the emergence of the criminal individual personality. The hard-hearted is mostly responsible for crime (Abdulla, 1998).

\subsection{The social theory}

This theory stresses the importance of the environment as well as the social, economic and cultural conditions in interpreting the behavior of criminals. Therefore, the social theory shifts the emphasis from the individual side (the criminal) to the source of crime, which is the social environment, including the prevailing social circumstances as well as the social relationships between man and society, since the individual criminal is not an isolated phenomenon by itself, but instead, it is the output of the surrounding community. The criminal is only a member of a group, and his crime is an act that violates to the laws of the group (Al-Seraj, 1983).

\subsection{Anomie theory (Durkheim)}

This theory interprets the crime as a natural social phenomenon that exists in all the societies and that the pattern and form of the crime differs from one time to another. It also confirms that the criminal is a natural component within social life components and that the relationship between the individual and society is restricted by two bases: the mechanical solidarity, and the organic solidarity.

1- The mechanical solidarity: it takes place between the individuals of the society, and includes the elements of their social life, such as values and thoughts.

2- The organic solidarity: the individuals of the society have different thoughts, beliefs and values, where every one of them has the freedom to share, and express his opinion which, in turn, creates a diversity in the functions and relationships within the society, and thus the communication and cooperation between the individuals decreases. When the control of "the collective conscience decreases, the solidarity becomes organic, just like the case in the developed societies (the city).

Durkheim confirms that social organization is a control system for the individuals' behavior in the society, he also asserts the inevitability of unusual circumstances that generate anomie, which refers to the loss of cooperation and mutual coordination as well as conflict between labor and wage system. Anomie emerges due to the failure in establishing effective relationships among individuals (Al-Seraj, 1983).

Meirton developed Durkheim's concept of anomie, defining it as a social status characterized by dispute between the objectives restricted by the society (Al-Mashahdani,2005). 
Meirton refers to the structural disorder in the society. According to him, deviation emerges when there is no social equilibrium between the accepted goals and the method that lead to achieving them which, in turn, creates a sense of stress as well as the inability to use the permitted methods for achieving the desired objectives, and eventually, leads the individual to commit crimes and delinquency. (Al-Sa'ati, 2005).

\subsection{Social Disintegration (Sellin Thorsten)}

This theory interprets crime based on what is prevalent in the societies of conflict and dispute- a prevailing characteristic in the developed societies, which creates a dysfunction in the behavior and eventually lead to crime. Sellin suggests that people in rural society live a simple style of life which is free from the complexes leading to the crime. Furthermore, rural people don't suffer from hard financial circumstances which could be a reason for committing crimes. On the contrary, the high costs of life that the individual experiences in the urbanized society makes him feel lonely and in need for others' help. Such circumstances could create envy and hatred against the people in his community; therefore, he may not feel hesitant to commit crime (Al-Wereikat, 2013).

Burgess suggests that the outskirts that are adjacent to the city are characterized by high rates of crime; these are the places where the poor live. Shaw Macky concluded that the rates of crime vary among the city's districts, where the crime is focused in the city center and the sites adjacent to the commercial center while they reduce as we move away from the center. The high crime rates are also linked with increasing unemployment rates. The reasons for the increasing number of crime in these outskirts are social disintegration and social complexity that are caused by urbanization as well as the considerable increase in the number of population (Al-Badaineh, 2003).

\section{The patterns of the crimes committed in Jordan}

The criminal statistical report issued by the criminal information department in the public security department during (2012-2016), as illustrated in table (1), shows that the crimes related to the financial domain were in the first rank among the patterns of the crimes committed in Jordan with a total of (89976) crimes, with a mean of (17995.2) and a percentage of $(69.09 \%)$, followed by the crimes that impose risk against the public management with a total of (12551) crimes, a mean of (251) and a percentage of $(9.63 \%)$, then the crimes that impose risk against the public security with a total of (1966.2) crimes and a percentage of $(7.54 \%)$, while the other crimes were in the last rank with a total of (1269) crimes, a mean of (253.8) and a percentage of $(0.97 \%)$. 


\section{Macrothink}

Journal of Studies in Education

ISSN 2162-6952

2019, Vol. 9, No. 1

Table 1. The patterns of the crimes committed in Jordan based on their type

\begin{tabular}{lllllllllll}
\hline The crime type & \multicolumn{3}{l}{ The year } & & & & Total & Mean & percentage \\
& 2012 & 2013 & 2014 & 2015 & 2016 & & \\
\hline
\end{tabular}

public trust

The crimes against funds

$21259 \quad 19849 \quad 17906 \quad 16431 \quad 14531 \quad 89976 \quad 17995.2 \quad \% 69.09$

The crimes against public

$\begin{array}{llllllll}1793 & 1903 & 3632 & 2416 & 2807 & 12551 & 251 & \% 9.63\end{array}$

administration

$\begin{array}{llllllllll}\text { The crimes against public } & 1657 & 1944 & 2492 & 1983 & 1755 & 9831 & 1966.2 & \% 07.54\end{array}$

safety

$\begin{array}{llllllllll}\text { The crimes } & \text { against } & 1289 & 1313 & 1285 & 1255 & 1536 & 6678 & 1335.6 & \% 5.12\end{array}$

manners and public ethics

Other crimes

$\begin{array}{llllllll}164 & 210 & 302 & 284 & 309 & 1269 & 253.8 & \% 0.97\end{array}$

Total

$\begin{array}{llllllll}18221 & 27349 & 27804 & 24244 & 22595 & 130213 & 3.397 .54 & \% 100\end{array}$

The patterns of the criminal crimes committed in the Jordan societies are also represented by the following (Al-Wereikat, et al, 2017):

1- Murder attempt

2- Intentional murder

3- Hitting that lead to death

4- Severe harm

5- Rape

6- Drug trafficking

7- Criminal robbery 


\section{The reasons leading to committing crime}

The most important reasons that lead to committing crime are(Abdullah, 2011) and (Al-Darawsheh, 2017):

1- Family disintegration: the family issues threaten the society security as well as stress and social disorganization. And disorder in the social structure affects the other social institutions and exposes the family to disintegration in some societies.

2- Bad partners: the individual's socialization with the bad people and being influenced by friends and school peers surpasses the effect of school and family, where the bad partners urges the individual to commit the criminal activities.

3- Poverty: it creates negative psychological emotions among the individuals if they have shortage in money and unable to provide the necessary needs for their families and are unable to provide the necessary housing; consequently, the individual is pushed towards committing the antisocial behavior. This doesn't mean that the rich don't commit financial crimes; indeed they commit such crimes as they seek more fun and richness.

4- Unemployment: it is one of the dangerous social issues that has negative consequences on the individual and society, and also lead to economic difficulties that cause loss in security, because the unemployed individual is unable to provide his requirements and do his duties towards others. These factors stimulates the individual to commit crimes since unemployment deprives the individual from the good living and forbids him from doing his human, social, national and ethical duty, eventually leading him to lose his entity.

5- Free times: the free time has a direct and indirect relationship with both individual and community. Therefore, the community and all the interested commissions have to supervise the process of organizing the free time which could be risky to individuals and expose them to drug and alcohol abuse as well as committing the deviant behaviors.

6- The lack of religious motives: the lack of religious motive leads the individual to commit crimes, since the religious education has an effective role in preventing crime and delinquency as well as supporting the social security of the society.

7- The feeling of inferiority, depression and deprivation, compulsion and neglect.

8- The media: the media could tell false news to individuals when the person realizes that the strong person is the one who takes his merited rights by power.

The researchers suggest that the dysfunction in the social structure, the weakness of the social relationships, the limited knowledge about the sanctions, the lack of religious motive as well as envy and hatred lead the individuals to commit delinquent behaviors; the worst images of the crimes committed in the Jordanian society are those listed under the name " blood flush" with its bad consequences related to burning the private possessions and houses and cutting down trees. It also converted from a dispute between to individuals into a dispute between groups what is called as " the five relatives in blood" in our Jordanian society. 


\section{The previous studies}

\subsection{Arabic studies}

(Al -Wereika et al,2017) conducted a study entitled by " the difficulties that face the inmates in the reform and rehabilitation centers and their needs in Jordan. the study sample consisted of (393) inmates. the results showed that the most important reasons leading the inmates to reform and related and rehabilitation centers are the crimes related to financial issues, followed by the crimes committed against man and finally the crimes violating manners and general ethics.

(Al -Darawsheh at al 2017) conducted a study which aimed at identifying the impact of the social variables on committing murder crime in the Jordan society from the perspective of the students of the Jordanian universities in order to a achieve the study objectives, the researchers developed a questionnaire to collect data and selected a random sample that consisted of (443) individuals. the results showed that there is an impact related to the social variables on committing the murder crime in the Jordan society, where family disintegration was in the first rank with a mean of (4.30) and a standard deviation of (7.69), followed by the lack of religious values, with a mean of (4.29), and a standard deviation of (7.03), and finally, the weak methods of social adjustment with a mean of (4.28), and a standard deviation of (6.45).the results showed that there are no statistically significant differences between the respondents' responses regarding the impact of social variables on committing the murder crime in the Jordanian society from the perspective of the students in the Jordanian universities attributed to the variables of (gender, educational level, and job) at $(\alpha \leq 0.05)$.

Mubarak, 2017 conducted a study entitled by "robbery crimes in Gaza governorates". The study sample consisted of (132) inmates in the reform and rehabilitation centers. The results showed that robbery crimes in Gaza follow a fluctuating nature, and that the main problem lies in the difficult economic circumstances, where $(68.2 \%)$ of the study sample individuals committed their crimes due to the difficult economic circumstances.

(Al-Shodaifat, et al, 2016) conducted a study which aimed at identifying the social factors which affect committing the crime in the Jordanian society from the perspectives of inmates in reform and rehabilitation center. The study sample was chosen randomly and consisted of (150) individuals. The results showed that $(48 \%)$ of the inmates belong to middle-income families, and (7\%) affiliate to rich families. Poverty, low income as well as economic status were motives for committing crimes. The results showed that the rates of crimes in the urban and industrial cities higher than those in Badia and rural areas, where (76\%) of the study sample individuals live in the big and industrial cities (Amman, Zarqa, Irbid, and Balqa'). The results revealed that $(48 \%)$ of the study sample individuals described the social relationships in their families as stressful and disintegrated, motivating them to commit crimes.

(Sara, 2016) conducted a study entitled by " the criminal behavior among murderers in the prisons of Al-Khartoum". The study sample was chosen randomly and consisted of (40) inmates. The study revealed the relationship between the motives of the criminal behavior 
among the murderers according to the variables of(age, crime type, inmate type, educational qualification, first-time inmate), which were based on sub motives and measures, such as(psychological, familial, aggressive, and economic).

(Al-Majali, 2016) conducted a study which aimed at identifying Mu'tah university employees attitudes towards the crime of human trafficking. The study sample consisted of (212) employees. The results showed that the mean for Mu'tah university employees attitudes towards the crime of human trafficking according to the social and economic variables was high. The results also showed that there are no statistically significant differences at $(\alpha \leq 0.05)$ regarding Mu'tah university employees attitudes towards the crime of human trafficking according to all the factors due to the demographic variables(gender, monthly income, and marital status).

(Al-Bazeghi, 2013) conducted a study entitled by " some psychological factors related to returning back to jail in Al-Riyadh. The study sample was chosen using the descriptive correlation approach and consisted of (181) inmates. The results showed that the majority of the inmates who returned back to jail with a medium-level education were about $(31.5 \%)$, followed by the secondary education $(29.2 \%)$, and finally the basic education stage with about $(10.3 \%)$. The results also showed that most of the individuals who returned back to jail were single (46.6\%) followed by the married (30.9\%) and finally the divorced (17.7\%).

(Hasnawy, 2012) conducted a study entitled by " the pattern and motives of the criminal women in the society". The researcher used the descriptive approach in content analysis due to the study nature. The researcher surveyed the editions of Al-Nahar newspaper for the year (2009), and selected two samples for two patterns of crimes(murder and the ethical crimes). The results showed that the rates of woman crimes in the highly-populated cities were high and that the majority of criminals are young, and the crime motives were economic, social, and psychological.

(Al-Abdullah, 2011) conducted a study entitled by the social factors affecting crime committing (a field study in Al-Ramadi). The results showed that the main reasons for committing crimes were the disintegration of family relationships, the bad financial circumstances, and the low income). The results revealed that $(70 \%)$ of the study sample suffer from disintegration in their family relationships, $(86.6 \%)$ had bad financial conditions. The results showed that the bad partners and the housing nature have a prominent role in stimulating the sample individuals to commit crime.

(Al-Barrak, 2010) conducted a study entitled by "the role of social factors in restricting the crime patterns in the Kingdom of Saudi Arabia". The study sample was chosen randomly and consisted of (158) inmates. The results revealed that the most common crimes in Hayil jail are drugs, robbery, followed by smuggling. The results showed that the disorganized families and bad partners as well as the low academic level lead to crime.

(Al-Najdawi, 2003) conducted a study entitled by "the crime and its relationship with unemployment and family problems in Jordan". The study population consisted of the inmates in Amman, Al-Jewaida, Berin and Zarqa reform and rehabilitation centers with a 
total of 1750 inmates. The study sample was chosen randomly and consisted of (150) inmates. The study used the social survey method. The results showed that the educational level has a significant impact on committing the criminal activity, where $(57 \%)$ of the sample individuals were with low educational levels, and that the low economic status as well as the low income of the family are within the factors that contribute to deviation. The results revealed that most of the inmates suffered from social problems and that poverty was in the first rank among these social problems. It was also evident that the robbery crime was in the first place $(37.3 \%)$, followed by the crime of fraud and forgery $(21.3 \%)$. The results contended that the bad partners have a prominent role with regard to urging individuals to commit crimes, with a percentage of $(71.7 \%)$.

\subsection{The foreign studies}

Vaish, Sharma,Sushil,Usman\&,2015) conducted a study entitled by " A Study of personality profile and criminal behavior in substance abusers". The results showed that there is an evident relationship between the criminal behavior on the one hand, and the economic, environmental, religious, social and family factors on the other. The results also revealed that the majority of the sample individuals who committed crimes were from the Hindu religion, and belong to a low cultural and social status; they also suffered from psychological diseases such as psychotics and neuroticism based on the psychological tests measured according to (DSM-IV). The study recommended about addressing the economic and social circumstances of the inmates as they represent the main motive for leading individuals towards the criminal behavior.

(Laajasalo, Ylipekka \& Nyholm,2013) conducted a study in Finland. The study sample consisted of (539) inmates who committed murder crimes during(1996-2004); the data included the reports of Psychiatry and criminal activities. The results showed that (21) of the sample individuals had personality disorders and suffered from obsessive-compulsive disorder as well as introversion.

(Grant.et al, 2007) conducted a study entitled by "murdering children among parents and inheritors". The study sample consisted of (387) children, less than 12 years old. The results showed that (111) children were killed by the biological mother, with a percentage of $(29.36 \%)$; the reasons for killing were related to anger, and revenge (4\%), insanity, and psychological disease $(36 \%)$, poverty and lack of social support as well as being marginalized by family and friends $(21 \%)$, the severe rage of the step mother as well as neglect $(21 \%)$. As for the method used for killing, they were: stabbing with a knife $(28 \%)$, shooting by pistol $(22 \%)$, smothering, sinking(15\%), and burning (15\%).

(Cecllia, 2003) conducted a study entitled by " the crime, the settlement and poverty". The study consisted of the rural women. The results revealed that the age category ranged between (23-46) years, and the majority were divorced and have (1-4) children, they are also housewives. The most prominent crimes committed by women are addiction to alcohol and drugs as well as drug trafficking, in addition to prostitution, robbery, property crimes and fraud. The results showed the motives of committing crimes are poverty and need, the low educational level, the unequal opportunities, as well as marginalization. The results showed 
that the television programs broadcast negative and unrealistic events.

(Leech, 2002) conducted a study entitled by " the reasons of rape" which aimed at detecting the reasons of rape as well as its social and psychological effects. The results showed that more that (778700) rape cases in the world during (1996-1997) and most offenders were addicted. However, the number is more than that since $(26 \%)$ of the cases weren't reported. The results also showed that $(28 \%)$ of rape cases take place against wives and friends, and $(35 \%)$ take place against the women by the relatives and addicted family members.

\section{The study methodology}

This study is different from the previous studies, where it attempted to identify the patterns and reasons if the committed crimes from the perspective of inmates in Ma'an reform and rehabilitation center. This study used the social survey that included the office survey in order to cite the theoretical framework of the study, as well as the field exploration to collect data using the study instrument and analyzing that statistically in order to answer the study question.

\subsection{The study population}

The study population consisted of the inmates in Ma'an reform and rehabilitation center in the south of Jordan, with a total of (350) inmates.

\subsection{The study sample}

The sample was selected randomly and the questionnaire was distributed to a number of inmates in Ma'an reform and rehabilitation center ; the study sample consisted of (105) inmates.

\subsection{The study instrument}

In order to achieve the study objectives, the researcher developed the study tool in order to measure the patterns of crime and identify the reasons underlying the crime committing from the perspective of inmates in Ma'an reform and rehabilitation center; it was developed based on previous studies, such (Al-Shodaifat, et al., 2011), (Al-Barrak, 2010) and (Al-Najdawi, 2003). The instrument was designed according to the five-point Likert scale (1-5).

The questionnaire consisted of the following:

11.3.1 The first part: it includes the demographic variables of the study sample (age, monthly income level, educational level, crime type), and measured by the questions from $(1-5)$.

11.3.2 The second part: it includes the most common crime patterns committed in the Jordanian society from the perspective of inmates in the rehabilitation and reform center; they are measured by the questions from (6-17).

11.3.3 The third part: it includes the most common reasons for committing crime in the Jordanian society from the perspective of inmates in the rehabilitation and reform center ; they are measured by the questions from(18-29). 
In order to identify the most common reasons and patterns leading to committing crimes in the Jordanian society from the perspective of inmates in Ma'an rehabilitations and reform center,the researcher calculated the means and the standard deviations taking into consideration the gradation of the used scale in the study as follows :

Always often sometimes never

Based on the above, the values of the means for this study will be used in order to account for the data as follows:

High

$3.49-5$ medium

$2.5-3.49$ low

$1-2.49$

Accordingly, if the mean value of the items is greater than (3.5), then the level of assessment is high, and this means the study population individuals agree with the item. If the value of the mean is (3.49-2.5), then the level of assessment is medium, and if the mean is less than(2.49), then the level of assessment is low.

\subsection{4 the validity of the study instrument}

In order to verify the validity of the study instrument, the researcher introduced it to (7) experienced arbitrators in the field of criminology, sociology, psychology and psychometrics, as well as educational sciences in the Jordanian universities. The arbitrators reached at an agreement rate of (84\%). Consequently, we considered the arbitrators' views and made the necessary adjustments, which were represented by paraphrasing some items.

\subsubsection{The reliability of the study instrument}

The reliability of the study instrument was verified using Cronbach Alpha coefficient by employing (SPSS), where Cronbach Alpha coefficient was (0.851). based on the reliability and validity results as well as the arbitrators' validity, it is evident that the study instrument is appropriate to be applied in this study.

\section{The statistical methods}

The study employed a number of statistical methods and tests in order to answer the study questions, and used the Statistical Package for Social Sciences (SPSS). The most important methods and tests are:

1- Descriptive Statistic Measure: it was used for describing the characteristics of the study sample, based on the frequency and percentages, as well as answering the study questions, and identifying the relative importance of the axes using the means and standard deviations.

2- Pearson correlation coefficient to examine the correlation relationships between the study variables.

3- One-way analysis of variance (ANOVA) 


\section{Macrothink}

\section{The study sample characteristics}

Based on the results in table (2) about the study sample characteristics, it is evident that those within the age category (20-29) years achieved the highest percentage (30.76\%), followed by (40-49) years old with a percentage (24.8\%), then (30-39) years old with a percentage $(23.07 \%)$, followed by those over 50 years old with a percentage $(17.30 \%)$, an finally those less than 20 years old with a percentage $(15.38 \%)$. As for the monthly income, those with (300-399) dinars each month, the percentage was (32.69\%), followed by those with less than (200) dinars a month with a percentage (28.84\%), then those with (201-299) dinars a month, where their percentage was $(26.35 \%)$, and finally those whose income was more than 400 dinars with a percentage of (17.30\%). As for the educational qualification, those with secondary certificate were in the first rank, with percentage of $(36.53 \%)$, followed by those a middle-school certificate with a percentage (32.69\%), then the illiterate, where their percentage was $(17.30 \%)$, followed by those with diploma certificate with a percentage (9.61\%), and finally those with bachelor degree with a percentage of (3.84\%). According to the marital status, the married were in the first place with a percentage of $(48.07 \%)$, then the single with a percentage of $(38.46 \%)$, followed by the widowers $(7.69 \%)$ and finally the divorced (5.76\%). 
Table 2. The distribution of the study based on the demographic variables

\begin{tabular}{|c|c|c|c|}
\hline The variable & Categories & Number & Percentage $\%$ \\
\hline \multirow[t]{6}{*}{ Age } & Less than 20 & 8 & $\% 15.38$ \\
\hline & $(20-29)$ & 16 & $\% 30.76$ \\
\hline & $(30-39)$ & 12 & $\% 23.07$ \\
\hline & $(40-49)$ & 9 & $\% 24.8$ \\
\hline & More than 50 & 7 & $\% 17.30$ \\
\hline & Total & 52 & $\% 100$ \\
\hline \multirow[t]{5}{*}{ Monthly income } & Less than 200 & 15 & $\% 28.84$ \\
\hline & $(201-299)$ & 17 & $\% 26.35$ \\
\hline & $(300-399)$ & 11 & $\% 32.69$ \\
\hline & More than 400 & 9 & $\% 17.30$ \\
\hline & Total & 52 & $\% 100$ \\
\hline \multirow{6}{*}{$\begin{array}{l}\text { Educational } \\
\text { qualification }\end{array}$} & Illiterate & 9 & $\% 17.30$ \\
\hline & Basic & 17 & $\% 32.69$ \\
\hline & Secondary & 19 & $\% 36.53$ \\
\hline & Diploma & 5 & $\% 9.61$ \\
\hline & Bachelor & 2 & $\% 3.84$ \\
\hline & Total & 52 & $\% 100$ \\
\hline \multirow[t]{5}{*}{ Marital status } & Single & 20 & $\% 38.46$ \\
\hline & Married & 25 & $\% 48.07$ \\
\hline & Widower & 4 & $\% 7.69$ \\
\hline & Divorced & 3 & $\% 5.76$ \\
\hline & Total & 52 & $\% 100$ \\
\hline
\end{tabular}

\section{The results}

14.1 The results related to the first question: What are the patterns of the crimes committed in the Jordanian society from the perspectives of inmates in Ma'an reform and rehabilitation center?

In order to answer this question, the researchers calculated the means, the standard deviations for the patterns of the crimes committed in the Jordanian society from the perspectives of inmates in Ma'an reform and rehabilitation center, and they were ordered in a descending order according to the level as illustrated in table (3). 


\section{Ml Macrothink}

Table 3. The patterns of the crimes committed in the Jordanian society from the perspectives of inmates in Ma'an reform and rehabilitation center

\begin{tabular}{rrrrr}
\hline The crime pattern & Mean & $\begin{array}{r}\text { Standard } \\
\text { deviation }\end{array}$ & $\begin{array}{r}\text { Order for } \\
\text { mean }\end{array}$ & $\begin{array}{r}\text { The level for } \\
\text { mean }\end{array}$ \\
\hline Murder & 4.88 & 0.47 & 1 & High \\
Drug trafficking & 4.75 & 0.42 & 2 & High \\
Robbery & 4.55 & 0.52 & 3 & High \\
Rape & 4.31 & 0.49 & 4 & High \\
Severe harm & 4.30 & 0.75 & 5 & High \\
Bad check & 4.29 & 0.71 & 6 & High \\
Violating houses & 3.22 & 0.78 & 7 & Medium \\
security & & 0.69 & 8 & Medium \\
Theft and bribe & 3.20 & 0.74 & 9 & Medium \\
Abduction & 3.18 & 0.72 & 10 & Medium \\
Incest & 3.01 & 0.73 & 11 & Medium \\
Total mean & 3.88 & 0.63 & - & High \\
\hline
\end{tabular}

Table (3) shows the most common crime patterns committed in the Jordanian society from the perspectives of inmates in Ma'an reform and rehabilitation center. In the first place there were murder crimes with a mean (4.88) and a standard deviation of (0.47), followed by drug trafficking with a mean (4.75) and a standard deviation of $(0.42)$, while robbery crimes were in the third place with a mean (4.55) and a standard deviation of (0.52). In the last rank, there were incest crimes with a mean (3.01) and a standard deviation of (0.63). The total mean for the crime patterns committed from the perspectives of inmates was (3.88) and a standard deviation of (0.63).

14.2 The results related to the second question: what are the reasons of the crimes committed in the Jordanian society from the perspectives of inmates in Maan reform and rehabilitation center?

In order to answer this question, the researchers calculated the means, the standard deviations for the reasons related to committing crimes in the Jordanian society from the perspectives of inmates in Ma'an reform and rehabilitation center, and they were ordered in a descending order according to the level, as illustrated in table (4). 


\section{Macrothink}

Table 4. The reasons for the crimes committed in the Jordanian society from the perspectives of inmates in Ma'an reform and rehabilitation center

\begin{tabular}{|c|c|c|c|c|}
\hline The reason & Mean & $\begin{array}{l}\text { Standard } \\
\text { deviation }\end{array}$ & $\begin{array}{l}\text { Order for } \\
\text { mean }\end{array}$ & $\begin{array}{l}\text { The level for } \\
\text { mean }\end{array}$ \\
\hline \multirow[t]{2}{*}{ Bad partners } & 4.81 & 0.42 & 1 & \\
\hline & & & & High \\
\hline Family disorganization & 4.65 & 0.40 & 2 & High \\
\hline Poverty & 4.51 & 0.51 & 3 & High \\
\hline unemployment & 4.30 & 0.47 & 4 & High \\
\hline Lack of religious motive & 4.25 & 0.69 & 5 & High \\
\hline $\begin{array}{ll}\text { Low } & \text { academic } \\
\text { achievement } & \end{array}$ & 4.22 & 0.66 & 6 & High \\
\hline Alcohol and drug abuse & 4.10 & 0.69 & 7 & High \\
\hline The desire to revenge & 4.09 & 0.70 & 8 & High \\
\hline Depressed emotions & 4.02 & 0.68 & 9 & High \\
\hline Sense of oppression & 4.00 & 0.72 & 10 & High \\
\hline $\begin{array}{l}\text { Sense of neglect by } \\
\text { others }\end{array}$ & 3.99 & 0.67 & 11 & High \\
\hline Total mean & 4.26 & 0.60 & - & High \\
\hline
\end{tabular}

Table (4) shows the reasons for committing crimes in the Jordanian society from the perspectives of inmates in Ma'an reform and rehabilitation center. In the first rank there were bad partners with a mean (4.81) and a standard deviation of (0.42), followed by family disorganization with a mean (4.65) and a standard deviation of (0.40), while poverty was in the third place with a mean (4.51) and a standard deviation of (0.51). In the last rank, there was the sense of neglect by others with a mean (3.99) and a standard deviation of (0.67). The total mean for the reasons of committing crimes from the perspectives of inmates was (4.26) and a standard deviation of (0.60).

\subsection{The results related to the third question}

Are there statistically significant differences at $(\alpha \leq 0.05)$ regarding the reasons leading to crimes committed in the Jordanian society from the perspectives of inmates in Ma'an reform and rehabilitation center due to the variables of age, income level, educational level, and marital status?

In order to answer this question, we performed the analysis of variance test, as illustrated in table (5) 


\section{Al Macrothink}

Journal of Studies in Education

ISSN 2162-6952

2019, Vol. 9, No. 1

Table 5. Analysis of variance to test the differences in the sample individuals responses regarding the reasons leading to committing crimes in the Jordanian society from the perspectives of inmates according to the demographic variables

\begin{tabular}{lllllll}
\hline The variable & Variance & Total & Total & Degree of & F & Significance level \\
& source & square & squares & freedom & value & \\
\hline Age & Intergroup & 3.5 & .95 & 3 & 3.8 & 0.11 \\
& Intra-group & 31.93 & .25 & 102 & & \\
& Intergroup & 0.62 & 0.19 & 3 & 3.34 & 0.14 \\
Income level & Intra-group & 35.85 & .269 & 102 & & \\
Academic & Intergroup & 1.30 & 0.98 & 3 & 3.26 & 0.26 \\
achievement & Intra-group & 35.32 & 030 & 102 & & \\
Marital status & Intergroup & 0.21 & .96 & 3 & 3.55 & 0.21 \\
& Intra-group & 40.25 & .27 & 102 & & \\
\hline
\end{tabular}

Statistically significant at $(\alpha \leq 0.05)$

Table (5) shows that there are no statistically significant differences at $(\alpha \leq 0.05)$ regarding the reasons leading to crimes committed in the Jordanian society from the perspectives of inmates in Ma'an reform and rehabilitation center due to the variables of age, income level, educational level, and marital status.

\section{Discussion}

The results showed that the most common crime patterns committed in the Jordanian society from the perspectives of inmates in Ma'an reform and rehabilitation center were murder crimes with a mean (4.88) and a standard deviation of (0.47), followed by drug trafficking with a mean (4.75) and a standard deviation of (0.42), while robbery crimes were in the third place with a mean (4.55) and a standard deviation of (0.52). In the last rank, there were incest crimes with a mean of (3.01) and a standard deviation of (0.63). The total mean for the crime patterns committed by inmates was (3.88) with a standard deviation of (0.63).

These results match with Al- Hasnawi (2012),(Al- Barak, 2010) and (grant et al,(2007). this could be attributed to the fact that the murder crime is one of the most serious problems that threaten the Jordanian society and have negative consequences on the individual and society. which are manifested by the collective punishment that take place via the formal patronage with regard to (the tribal peregrination) that is considered as one of the toughest punishment that could take place against the innocent individuals of the offenders family, in addition to the drugs crimes that are becoming more prevalent and have devastating effects 
on the individual and the community, is it represents one of the basic motives leading to murder crime for obtaining specific private interests, and the robbery crimes that overstrained the Jordanian society.

The results also revealed the reasons for committing crimes in the Jordanian society from the perspectives of inmates in Ma'an reform and rehabilitation center, where the bad partners were in the first rank with a mean of (4.81) and a standard deviation of (0.42), followed by family disorganization with a mean (4.65) and a standard deviation of (0.40), while poverty was in the third place with a mean (4.51) and a standard deviation of (0.51). In the last rank, there was the sense of neglect by others with a mean (3.99) and a standard deviation of (0.67). The total mean for the reasons of committing crimes from the perspectives of inmates was (4.26) and a standard deviation of (0.60).

These findings match with (Al- Wereikat, et al, 2017) (Al-Darawsheh, et al, 2017),(Sara,2016),(Vaish, Sharma, Sushil, and Usman, 2015),( Al- Bazighi,2013), (Al-Abdullah, 2011),(Al-Shabrami, 2010), (Kathleen and Bruce, 2005), and (Cecllia 2003).

The researchers suggest that the bad mates have an important role in causing the deviant behaviors, as well as the weak family parenting and supervision which lead to family disorganization. poverty is also a main factor leading to the deviant behaviors that devastates the society.

The researchers also suggested that these results match with the anomie theory which emphasizes the inevitable conditions that lead to the anomie, which means the lack of cooperation and mutual coordination. The anomie also results from the failure in establishing effective relationships between the individuals in the society. The results also match with the social disintegration theory as it contends that people in the rural community have a simple life style that doesn't stimulate people to commit crimes, they also don't have hard financial conditions that urge them to commit crimes. However, the high demands and costs in the life of the urban societies generate the sense of loneliness and the need for others' help; therefore, stimulate envy and hatred among those individuals and consequently lead to committing crimes.

\section{Recommendations}

1- Promoting the role of the family and constructing it by focusing on its role in the process of socialization in cooperation with the public institutions so as to have an educated generation that realizes his responsibility and role in the society as well as maintaining the values, traditions, social and religious norms that reduce crime and delinquency.

2- Providing work opportunities in order to unemployment which has a prominent role in reducing the crime rates.

3- Activating the role of mosques, clubs, and youth centers with regard to educating the youth about the risks of bad partners and the negative consequences of that on the individual and society. 
4- Providing the basic services as well as the luxury sites and imposing more supervision and control to reduce crime rates.

\section{References}

Abdullah,Majdi, Ahmad Mohammad. (1998). The criminal behaviors and their dynamics, University knowledge House, Cairo, 177.

Abu Zahra, Mohammad. (1998). Crime and Punishment in Islamic Jurisprudence, Arab Thought House, Cairo, p. 19.

Ahmad Mohammad Sa'eid, Sarah. (2016). The motives of the criminal behavior among the murderers in the prisons of Al-Khartoum, unpublished Master thesis in criminal psychology, National University of Al-Rabat, Algeria.

Al-Abdullah, NouriSa'doun. (2011). The social factors affecting the crime, Al-Anbar University.

Al-Badaineh, DhiabMousa. (2003). The reality of crime future in the Arab world, Naif Arab Academy, Al-Riyadh, p. (97).

Al-Badaineh, MousaDhiab. (2011). Crimes in the Age of Globalization, Police Research Center, Al-Sharjah.

Al-Barrak, FahadAdham. (2010). The Role of Social Factors in Challenging the Crime Patterns in Saudi Arabia, Unpublished Thesis, the Faculty of Social Sciences, Mu'tah University, Al-Karak, Jordan.

Al-Darawsheh, Abdullah Salem, Al-Mawajdeh, \& Murad Abdullah. (2017). The Effect of Social Variables on Committing Murder Crime in the Jordanian Society. Al-Hussein Bin Talal University Journal, 3(1).

Al-Essawi, Abdul-Rahman. (1992). A Research in Crime, Dar Al-Nahdha Al-Arabiya, Beirut, p. 25.

Al-Hassan, Ihsan. (1993). Criminology, an analytical study about the social factors of crime, Baghdad university, Iraq, p.26

Al-Majali, Ahmad Abdul-Salam. (2016). The employees' attitudes Towards Human Trafficking. The Jordanian Journal of Social Sciences, 9(1), 16.

Al-Mashhadani, Akram Abdul-Razzaq (2005). The Reality and Trends of Crime in the Arab World, $1^{\text {st }}$ Edition, Naif Arab Universit,y, Al-Riyadh, p.45.

Al-Najdawi, Mousa. (2003). Crime and Its Relationship to Unemployment And Family Problems in Jordan, Unpublished Master Thesis, the University of Jordan, Jordan.

Al-Saati, Samia Hassan. (2005). Criminal sociology, Arab Thought House, Cairo, p.28.

Al-Sayid, Jabir Awadh, Abdul-Mawjood, \& Al-Hasan. (2004). The Deviation and Crime in a Changing World, The New University Library, Cairo, p. 134. 


\section{MInstitute Macrothink $_{\text {Int }}$}

Al-Seraj, Abboud. (1983). Criminology and the science of punishment, $1^{\text {st }}$ edition, Kuwait University, p. 264.

Al-Shabrami, Aiman Mohammad Suleiman. (2010). the relationship between amnesty and return to crime, unpublished Master Thesis, Naif Arab University for Security Sciences, Al-Riyadh.

Al-Shodifat, Ameen Jabir, \& Al-Rashidi Mansour Abdul-Rahim. (2016). The social factors affecting the commission of the crime from the perspective of prisoners in the reform and rehabilitation centers. the Journal of Studies, Humanities and Social Sciences, 43, appendix 5 .

Al-Wereikat, \& Ayid Awwad. (2013). the theories of criminology, Wa'el House for publishing and distribution, Amman.

Al-Wereikat, Ayid, Al-Jazi, Jamal, Al-Olaimat, Homoud, \& Abu Ayyash, Riham. (2017). problems faced by the inmates of reform and rehabilitation centers in Jordan, the Journal of Studies and Research, the Arab Journal of the Humanities and Social Sciences is.

Badawi, Mahmoud Qassim. (1974). the rules of the curriculum in sociology, the Egyptian Renaissance Library, Cairo, (p. 15-16).

Cecilia, Shubert. (2003). Female Crime and Poverty, stolen opportunities of Athabasca.

Durkheim. (2002). Les Regles de La Method Sociologies, ed, Macintoch, Quebec, p45.

Goraiben Mohammad SayidAhmed, \& Jaber Mohammad Samia. (2003). Criminology and Deviant Behavior, The University Knowledge House, Alexandria, p. 30.

Grant et al. (2007). Children Killed by genetic parents versus stepparents, Mental health Center, Canada.

Hasnawi, Khairiya. (2012). The patterns and motives of women's crime, unpublished master's thesis, the Faculty of Arts, Baji Mokhtar University, Ennaba.

IbnMandhour. (1994). Lisan Al-arab, $3^{\text {rd }}$ edition, Beirut p.45

IbnTaymiyya, Ahmad Abdul-Halim, \& Al-Noraniah. (2005). A collection of IbnTaymiyya fatwas, the first edition, Al-Sunnah Mohammadiyah library, Egypt, Cairo.

Jaber, Samia. (1998). Delinquency and the society, Arab Knowledge House, Cairo, p.170

Jaber, Samia. (2007). Crime, law and society. University Knowledge House, Cairo, p.7.

Kathlean, Bruseis. (2005). Resource for dropout from drug abuse treatment symptoms personality and motivation, addictive behaviors.

Laajasalo,T,Ylipekka, M., \& Nyholm,H. (2013). Homicidal Behaviour Among People With Avoidant, Dependent and Obsessive - Compulsive (Cluster C) Personality Disorder. Journal of Criminal Behavior and Mental Health, 23, 18-29. https://doi.org/10.1002/cbm.1844

Leech.(2002),American Journal of public Health Justice studies, V.O.In.4.PP 46-69. 


\section{Macrothink}

Journal of Studies in Education

ISSN 2162-6952

2019, Vol. 9, No. 1

Madas, Farouq. (2003). The Dictionary of Sociological Terminology, Dar Madani for Printing and Publishing, p. 180.

Mubarak, Wassim Ahmad Hassan. (2017). The crime of robbery in Gaza governorates, a study in the geography of crime, unpublished master thesis, the Islamic University of Gaza.

Nashaat, Ibrahim Akram. (1998). The General Rules in the Comparative Penal Act, Al-Fityan Printing Press, Baghdad.

Vaish,S.Sharma,D,.Sushil,C,Usman,N.and Sudarsanan. (2015). A Study of personality profile and criminal behavior in substance abusers. Industrial Psychiatry Journal, 24(1). https://doi.org/10.4103/0972-6748.160960

Zein Al-Deen, \& Ibn Al-Sheikh Fareed. (1995). Criminal Psychology. The Department of University Publications, Algeria.

Zuraiqat, Nisreen. (2009). The $6^{\text {th }}$ annual report about reform and rehabilitation centers in the Hashemite Kingdom of Jordan, the National Center for Human Rights. 